\title{
Asymptomatic Clostridium difficile colonization: epidemiology and clinical implications
}

\author{
Luis Furuya-Kanamori ${ }^{1}$, John Marquess ${ }^{2,3}$, Laith Yakob ${ }^{4}$, Thomas V. Riley, ${ }^{5,6}$, David L. Paterson ${ }^{7}$, Niki F. Foster ${ }^{6}$,
} Charlotte A. Huber ${ }^{7}$ and Archie C. A. Clements ${ }^{1 *}$

\begin{abstract}
Background: The epidemiology of Clostridium difficile infection (CDI) has changed over the past decades with the emergence of highly virulent strains. The role of asymptomatic C. difficile colonization as part of the clinical spectrum of CDI is complex because many risk factors are common to both disease and asymptomatic states. In this article, we review the role of asymptomatic C. difficile colonization in the progression to symptomatic CDI, describe the epidemiology of asymptomatic $C$. difficile colonization, assess the effectiveness of screening and intensive infection control practices for patients at risk of asymptomatic C. difficile colonization, and discuss the implications for clinical practice.
\end{abstract}

Methods: A narrative review was performed in PubMed for articles published from January 1980 to February 2015 using search terms 'Clostridium difficile' and 'colonization' or 'colonisation' or 'carriage'.

Results: There is no clear definition for asymptomatic CDI and the terms carriage and colonization are often used interchangeably. The prevalence of asymptomatic $C$. difficile colonization varies depending on a number of host, pathogen, and environmental factors; current estimates of asymptomatic colonization may be underestimated as stool culture is not practical in a clinical setting.

Conclusions: Asymptomatic C. difficile colonization presents challenging concepts in the overall picture of this disease and its management. Individuals who are colonized by the organism may acquire protection from progression to disease, however they also have the potential to contribute to transmission in healthcare settings.

Keywords: Clostridium difficile, Carrier state, Asymptomatic, Infection

\section{Background}

Clostridium difficile is a Gram-positive, spore-forming, anaerobic bacillus that was first described in 1935 as part of the intestinal flora of newborn infants [1]. C. difficile is recognized as one of the most important pathogens in hospital and community healthcare settings, with a steadily rising global incidence of infection and concordant increase in mortality [2,3]. The Centers for Disease Control and Prevention in the USA have assigned $C$. difficile as an urgent threat because of its association with antibiotic use and high mortality and morbidity [4].

\footnotetext{
*Correspondence: director.rsph@anu.edu.au

${ }^{1}$ Research School of Population Health, The Australian National University, Building 62 Mills Road, Canberra ACT 2601, Australia

Full list of author information is available at the end of the article
}

The clinical spectrum of symptomatic $C$. difficile infection (CDI) ranges from mild diarrhea to severe complications such as pseudomembranous colitis, toxic megacolon, bowel perforation, sepsis, and death [5]. Symptomatic CDI is mediated through the production of toxins that are cytotoxic to epithelial cells of the colon, causing extensive inflammation and epithelial tissue damage to the host [6]. These toxins (toxins A and B) are implicated as the major virulence factors of $C$. difficile. An additional putative virulence factor, the binary toxin, is produced by some strains, particularly the more virulent epidemic strains such as BI/NAP1/027, and may also be present in the absence of toxin A or toxin B [7].

Asymptomatic $C$. difficile colonization is the condition where $C$. difficile is detected in the absence of symptoms 
of infection. It has been proposed that asymptomatic $C$. difficile colonized patients may be protected from progression to infection because they can mount a humoral immune response to clostridial toxins [8]. However, asymptomatic $C$. difficile colonized patients potentially act as an infection reservoir and may present a risk to others $[9,10]$. The number of colonized patients is higher than symptomatic CDI cases among hospital patients, particularly when disease is endemic [11-13]. The prevalence of asymptomatic $C$. difficile colonization varies depending on a number of host, pathogen, and environmental factors. These features of asymptomatic $C$. difficile colonization are important to establish the contribution that asymptomatic $C$. difficile colonized patients make as potential vehicles of transmission of $C$. difficile in healthcare environments, particularly with the global spread of emergent hypervirulent toxigenic strains [14].

Few studies have synthesized evidence on the role and importance of asymptomatic $C$. difficile colonization in the progression to symptomatic CDI, the transmission of infection, or the challenges to CDI control. Therefore, we have reviewed published literature (Additional file 1) describing asymptomatic $C$. difficile colonization to better understand the prevalence, risk factors for colonization, mechanisms that may protect colonized patients from progression to symptomatic CDI or recurrent disease and the risk asymptomatic $C$. difficile colonized patients pose to non-colonized patients.

\section{Definition of symptomatic C. difficile infection and asymptomatic $C$. difficile colonization}

It is generally accepted that positive assays for $C$. difficile toxins are indicative of active disease and that the toxins are responsible for clinical symptoms $[15,16]$. A validation study comparing reference tests for $C$. difficile (toxin assay positive versus cytotoxigenic $C$. difficile culture positive/toxin assay negative) showed that detection of toxins was associated with more severe CDI outcomes [17]. However, it has also been reported that patients with positive toxin assays can remain symptomless $[8,10,18]$. Therefore, the sole presence of $C$. difficile toxins is insufficient for a diagnosis of the disease. Consequently, symptomatic CDI has been defined as:

- The presence of diarrheal symptoms (three or more unformed stools in 24 or fewer consecutive hours) and either

$O$ a stool test result positive for $C$. difficile toxins or

$\bigcirc$ detection of toxigenic $C$. difficile, or

$O$ colonoscopic findings demonstrating pseudomembranous colitis [19].

To our knowledge there is no clear definition for asymptomatic CDI and the terms carriage and colonization are
Table 1 A description of different case definitions for asymptomatic colonization and carriage with C. difficile

\begin{tabular}{|c|c|c|}
\hline Term used & Case definition & Study reference \\
\hline \multirow[t]{4}{*}{ Colonization } & $\begin{array}{l}\text { Patients with symptomless } \\
\text { colonization were defined as } \\
\text { symptom-free, excluding } \\
\text { patients recovering from } \\
\text { C. difficile associated diarrhea. }\end{array}$ & Shim, 1998 [8] \\
\hline & $\begin{array}{l}\text { Asymptomatic } C \text {. difficile } \\
\text { colonization was defined as } \\
\text { a positive stool culture for } \\
\text { C. difficile in the absence } \\
\text { of diarrhea. }\end{array}$ & Loo, 2011 [13] \\
\hline & $\begin{array}{l}\text { A case of toxigenic } C \text {. difficile } \\
\text { colonization was defined as } \\
\text { an asymptomatic individual } \\
\text { with } t c d B \text { gene detected in a } \\
\text { fecal sample by real-time PCR }\end{array}$ & Hung, 2012 [109] \\
\hline & $\begin{array}{l}\text { Was not specifically defined } \\
\text { and did not distinguish between } \\
\text { colonization and infection. One } \\
\text { colonized case was symptomatic } \\
\text { at sampling time (personal } \\
\text { communication). }\end{array}$ & Arvand, 2012 [30] \\
\hline \multirow[t]{3}{*}{ Carriage } & $\begin{array}{l}\text { Asymptomatic carriage was } \\
\text { defined as a positive stool } \\
\text { culture or cytotoxin test and } \\
\text { the absence of diarrhea during } \\
\text { hospitalization and during a } \\
\text { 30-day period after discharge. }\end{array}$ & Kyne, 2000 [18] \\
\hline & $\begin{array}{l}\text { Asymptomatic carriage was } \\
\text { considered when C. difficile or } \\
\text { its cytotoxin was detected in } \\
\text { stool from persons without } \\
\text { gastrointestinal symptoms. }\end{array}$ & Simor, 1993 [67] \\
\hline & $\begin{array}{l}\text { Carriers were defined as positive } \\
\text { for a toxigenic } C \text {. difficile screening } \\
\text { test during the study period in the } \\
\text { absence of a clinician ordered } \\
\text { toxin screen determined by } \\
\text { electronic medical record review. } \\
\text { Carriers were categorized as } \\
\text { persistent, transient, or indeterminate. }\end{array}$ & Curry, 2013 [75] \\
\hline
\end{tabular}

often used interchangeably. Table 1 provides case definitions for asymptomatic carriage and colonization identified in this review to illustrate the heterogeneity of the definitions used by different the authors and that both terms have been used without distinction. For the sake of clarity, while maintaining conventions of previous studies, we recommend the following definition for asymptomatic $C$. difficile colonization:

- The absence of diarrhea (or if present, attributable to a cause other than CDI) without colonoscopic or histopathologic findings consistent with pseudomembranous colitis, and either

$\bigcirc$ the detection of $C$. difficile or

$O$ the presence of $C$. difficile toxins. 
Novel to this definition of asymptomatic C. difficile colonization is the acknowledgment that symptoms associated with CDI can arise from alternative underlying conditions. Diarrhea commonly affects hospitalized patients and in the majority of the cases is attributable to non-infectious (e.g. medication side-effects, inflammatory bowel disease) and infectious causes other than CDI [20]. The proportion of cases of nosocomial diarrhea attributable to CDI may be within the range of 20 to $25 \%$ $[21,22]$. Identification of the etiology of diarrhea (or even to rule out $C$. difficile) could be challenging, particularly in critically ill patients. In cases where the underlying cause(s) of diarrhea cannot be identified (or CDI remains as a differential diagnosis), we suggest the use of algorithms such as the one proposed by Polage and colleagues [20]. They suggested that regardless of their antibiotic exposure status, CDI should be considered in all patients with clinically significant diarrhea. The evaluation of a patient should start by verifying the presence of diarrhea; the frequency, consistency, volume of stool, and duration of diarrhea should be taken into account along with associated symptoms/signs such as cramping, dehydration, fever, hypotension, or sepsis. If no clear infectious cause is identified, the medical history must be reviewed for non-infectious or iatrogenic (e.g. laxative overdose) causes.

There is no evidence that non-toxigenic $C$. difficile strains can cause disease [23]. In studies reporting CDI from patients harboring non-toxigenic strains, the cultured organisms were mixed with toxigenic stains and could not definitively be associated with disease [24, 25]. Hence, individuals with diarrhea who test positive only for non-toxigenic strains of $C$. difficile should be considered asymptomatically colonized unless there is supporting evidence of disease, such as endoscopic findings consistent with pseudomembranous colitis. In addition, colonization can be transient or long term often depending on the extent and frequency of exposure to $C$. difficile.

\section{Epidemiology}

Prevalence estimates of asymptomatic C. difficile colonization vary considerably between different patient groups (Table 2). Among healthy adults with no prior risk factors for CDI, asymptomatic $C$. difficile colonization prevalence varied between 0 and $15 \%$ [15, 26-33]. The study reporting $15 \%$ was a prospective cohort study carried out on seven groups of healthy individuals representing various occupations in Japan [32]. The range of asymptomatic C. difficile colonization prevalence among groups of study subjects was 4 to $15 \%$; the groups comprised university students, hospital workers, company employees, and defense force personnel. Among healthy newborns and infants, the prevalence of asymptomatic $C$. difficile colonization varied between 18 and $90 \%[15,34]$.

Few studies have examined asymptomatic C. difficile colonization in acute hospital care settings. In 1982, Gerding and colleagues detected 43/146 (29\%) patients colonized with non-toxigenic $C$. difficile strains [22]. Over the course of 10 years (1982-1991), Belmares and colleagues reported overall colonization with non-toxigenic strains in $10 \%$ of the patients (ranged from $5 \%$ in 1982 to $18 \%$ in 1984) [35]. Most studies reporting asymptomatic C. difficile colonization have targeted elderly patients in dedicated long-term care facilities (LTCFs). Prevalence of asymptomatic $C$. difficile colonization among elderly residents ranged from 0 to $51 \%$, possibly because CDI is often endemic in units or institutions with elderly patients $[9,30,36,37]$.

Among adults, the highest prevalence of asymptomatic C. difficile colonization has been reported in patients with

Table 2 Prevalence of asymptomatic C. difficile colonization in different populations

\begin{tabular}{lll}
\hline Population type & Range of carriage rates & References \\
\hline Healthy neonates and infants & $18-90 \%$ & {$[34,110-113]$} \\
Healthy adults - general population & $0-15 \%$ & {$[15,26-33]$} \\
Elderly in long-term care facilities, chronic care, or nursing homes & $0-51 \%$ & {$[9,30,37,66,67,70,114-116]$} \\
Hospital & $0.6-15 \%$ & {$[26,68,69,114,117,118]$} \\
$\quad$ Elderly & $4-29 \%$ & {$[10,13,18,22,73,79,91,105,106,109,119-121]$} \\
Inpatients (not specifically elderly) & $11-50 \%$ & {$[43,45]$} \\
Rehabilitation (spinal) & $4 \%$ & {$[122]$} \\
HIV & $0-13 \%$ & {$[26,32,123]$} \\
Healthcare workers & $18-47 \%$ & {$[38-41]$} \\
Cystic fibrosis & $17 \%$ & {$[124]$} \\
Hospital surgical patients on antibiotic prophylaxis & $7 \%$ & {$[125]$} \\
Intensive care & $11 \%$ & {$[95]$} \\
IBD (ulcerative colitis or Crohn's disease) & $8 \%$ & {$[94]$} \\
Hematological malignancies &
\end{tabular}


cystic fibrosis (CF) and in spinal/brain injury rehabilitation. Asymptomatic $C$. difficile colonization prevalence ranged from 18 to $47 \%$ in studies among CF patients, substantially higher than other clinical subgroups (e.g. surgical patients) or general hospital inpatients [38-42]. In a case-control study, Bauer and colleagues found 26/55 (47 \%) CF patients were asymptomatically colonized [38]. Yahav and colleagues reported 14 toxin-positive asymptomatic $C$. difficile colonized patients without evidence of diarrhea in a study of $30 \mathrm{CF}$ patients compared to no toxin-positive individuals among non-CF patients [41]. Welkon and colleagues reported asymptomatic $C$. difficile colonization in 19/99 CF patients (19\%), with 12 strains being toxigenic [40]. Another study of CF patients reported asymptomatic $C$. difficile colonization in 12/37 (32\%) patients, rising to $43 \%$ if patients were treated with antibiotics [39]. The heightened vulnerability of CF patients to asymptomatic $C$. difficile colonization rather than to disease has been attributed to an electrolyte transport defect in epithelial cells that may offer protection from the effects of clostridial toxins [41].

Rehabilitation patients also had higher asymptomatic $C$. difficile colonization prevalence than other groups. In one study, 11/22 (50 \%) spinal cord rehabilitation patients were colonized and remained asymptomatic [43]. The asymptomatic $C$. difficile colonized patients in this study also had a significantly greater length of stay (median 57 days) compared to non-colonized patients (median 6 days). Stevens and colleagues found that for 7-day increments in length of stay, the risk of healthcare-associated CDI increased by $10 \%$ [44]; this implies that on average, spinal cord rehabilitation asymptomatic $C$. difficile colonized patients will be at $52 \%$ increased risk of developing CDI compared to non-colonized $C$. difficile patients. Another study of asymptomatic C. difficile colonization prevalence on admission to a rehabilitation ward reported that 9/54 (17 \%) patients without prior colonization became colonized after admission [45]. Of these nine patients, six showed no symptoms of diarrhea. The increased colonization rate among this group of patients is thought to result from the rehabilitation therapy where group activities and socialization are encouraged, facilitating transmission.

\section{Mechanism of colonization with C. difficile}

The first stage in asymptomatic $C$. difficile colonization is the ingestion of $C$. difficile spores [46-48]. The spores survive the gastric acid and germinate into vegetative cells in the anaerobic environment of the colon. C. difficile has been isolated from samples of human jejunum, however the primary reservoir is the large intestine [49]. Vegetative $C$. difficile cells penetrate the mucus layer in the large intestine using flagella and enzymatic degradation of the colonic extracellular matrix [48]. Once the mucosal layer has been breached, in vitro assays have demonstrated that adhesion of $C$. difficile cells to intestinal epithelial cells is facilitated by bacterial surface layer proteins [50].

For colonization with vegetative $C$. difficile cells to occur, there must be a disruption of the normal intestinal microbiota which usually provides colonization resistance against $C$. difficile [51, 52]. The inhibitive effect of the natural gut microbiota may occur through competition for space and nutrients or the production of compounds that inhibit C. difficile proliferation [53]. The concept of colonization resistance is important to understand the mechanisms that result in the development of disease. Therefore, there is potential to introduce non-pathogenic organisms as probiotic agents or non-toxigenic $C$. difficile strains to compete with toxigenic $C$. difficile strains as novel prevention and treatment strategies [54, 55]. However, Brouwer and colleagues have challenged this concept as they found that transconjugation of the pathogenicity locus can occur from toxigenic to non-toxigenic $C$. difficile strains [56].

\section{Toxin production and asymptomatic colonization}

Secretion of toxins A and B usually occurs once $C$. difficile reaches the stationary phase. The first essential step for these toxins to exert their effects is binding to receptors on gut epithelial cells [6]. Disease symptoms commence with toxin catalysis in the cytosol. The catalyzed toxin products inactivate guanosine triphosphate binding Rho proteins [6]. The subsequent depolymerization of the actin cytoskeleton elicits a cellular response that includes neutrophil infiltration, resulting in inflammation, and the subsequent release of cytokines and interferon gamma $[57,58]$. Cell death occurs by apoptosis following disaggregation of the actin cytoskeleton [59]. Consequently, extensive colonic inflammation and epithelial tissue damage occur, leading to rapid fluid loss into the large intestine, manifesting as acute diarrhea [6].

The role and importance of toxins A and B in progression to the disease state has been subject to debate. In early studies using hamster models, purified toxin A was shown to elicit symptoms consistent with disease, whereas toxin B would only elicit a response if coadministered with toxin A [60]. Consequently, it was suggested that toxin $\mathrm{B}$ exerted an effect following initial tissue damage by toxin $\mathrm{A}$. The recovery of toxin A-negative, toxin B-positive strains from symptomatic patients has challenged the view that toxin $\mathrm{A}$ is the dominant virulence factor in CDI [61, 62]. Recent work with animal models using antibodies against toxins $\mathrm{A}$ and $\mathrm{B}$ showed that administration of anti-toxin $B$ antibodies either alone or in combination with anti-toxin A was more effective at preventing the development of gastrointestinal symptoms consistent with CDI [63]. Lyras and colleagues constructed 
mutant isogenic strains of $C$. difficile capable of producing either toxin $\mathrm{A}$ or toxin $\mathrm{B}$. The toxin A producing strains lost their pathogenicity whereas the toxin B producing stains were as pathogenic in animal models as wild type strains [64]. However, another group using similar gene knockout methods to generate mutant strains produced conflicting findings with a role for both toxins $\mathrm{A}$ and $B$ [65].

Toxigenic strains of $C$. difficile are the most prevalent among colonized patients; early studies cultured stool specimens and using enzyme immunoassay (EIA) or cell culture cytotoxicity neutralization assay reported the proportion of toxigenic strains among asymptomatic colonized patients was in excess of $50 \%$ [31, 39, 40, 66-69]. These findings have been corroborated in later studies using real-time polymerase chain reaction (PCR) $[27,29,30,32,70]$. It is important to note that both EIA and PCR methods specifically target toxigenic $C$. difficile strains and could therefore bias results reporting a higher prevalence of these strains [71].

\section{Duration of the colonized state}

There is limited information about the duration over which individuals remain asymptomatic after coming in contact with $C$. difficile spores or the time taken to revert to a non-colonized state. In a randomized placebocontrolled trial, Johnson and colleagues compared the efficacy of vancomycin and metronidazole for eradication of $C$. difficile in asymptomatic colonized patients. Sixty, 80 and $100 \%$ of the patients in the placebo group were negative for $C$. difficile after 40, 70 and $>90$ days follow-up, respectively [72]. In a prospective study, Samore and colleagues [73] compared the incidence of colonization in surgical, medical and intensive care wards. Thirty two colonized patients were followed on a weekly basis until they were discharged; $84 \%$ of the colonized patients remained culture positive with median duration of colonization of 8.5 days (range 7-29 days). The study also showed that $3 / 20$ (15\%) of the patients colonized with non-toxigenic strains, none of whom developed diarrhea, were positive for toxigenic strains at follow-up. Longer-term colonization and transmission was investigated among 1234 healthy Japanese volunteers, who included university students, hospital staff, and company employees [32]. Follow-up was performed on 38 asymptomatic patients between 5 and 7 months later. Of these 38 cases, $C$. difficile was re-isolated from $12(32 \%)$ individuals, half of whom yielded the same PCR ribotypes and pulsed-field gel electrophoresis types as previously. In a subsequent study by the same authors, a 6-month follow-up of 18 colonized healthy students found 10 (56\%) were no longer colonized and 8 (44\%) were colonized more than once, of whom 3 (38\%) harbored the same strain [27].
These findings suggest that there is marked variation in duration of the colonized state, however the role of repeated exposure from the environment or other colonized individuals was not investigated. Limited longitudinal data available about asymptomatic C. difficile colonization warrants further epidemiological studies to investigate the persistence of colonization and to understand the role of re-exposure to the organism over time.

\section{Transmission from colonized patients}

Person-to-person transmission in hospital wards, environmental contamination, and carriage of $C$. difficile on the hands of healthcare workers have been described extensively [74-77]. The main modes of transmission are by the fecal-oral route and direct contact with contaminated surfaces and fomites [78], although transmission between healthy individuals who are asymptomatically colonized has also been reported [32].

Spores from asymptomatically colonized patients are a potential source of CDI and may contribute to the transmission reservoir [9] and studies have clearly demonstrated that transmission from asymptomatically colonized patients can occur $[75,79]$. Curry and colleagues investigated transmission potential of asymptomatic C. difficile colonized patients using multiple-locus variable number tandem repeat analysis. They found that $29 \%$ of isolates from hospitalassociated CDI cases were highly related to isolates from asymptomatic $C$. difficile colonized patients [75]. Clabots and colleagues reported that patients admitted from home without prior hospitalization in the previous month had the lowest prevalence of asymptomatic $C$. difficile colonization (6\%) but, because they represent the majority of admissions, they contributed the second-highest total number of C. difficile introductions to hospital, after patients readmitted to hospital within 30 days [79]. Similarly, the length of stay in hospital can also influence transmission. Fecal excretion of $C$. difficile spores occurs for up to 6 weeks following resolution of CDI symptoms [80, 81]. Furthermore, Riggs and colleagues demonstrated that even colonized patients who did not develop disease during a 6 months follow-up period were shedding spores into the environment [9]. The current CDI clinical practice guidelines from the Society of Healthcare Epidemiologists of America (SHEA) recommend maintaining contact precautions only until resolution of diarrhea. It has been suggested that contact precautions should be extended until time of discharge for patients recovering from CDI. However, there is no conclusive evidence to support extending contact precautions following CDI while patients remain asymptomatic during their hospital stay [81].

Asymptomatic C. difficile colonized patients in hospital have the potential to contaminate the environment and subsequently infect others [75]; however the transmission potential is lower in asymptomatic C. difficile 
colonized patients than in those patients with active disease [10]. In one prospective study of acquisition rates in an endemic CDI setting, 38/128 (29 \%) environmental samples from hospital rooms occupied by asymptomatic C. difficile colonized patients were contaminated compared to $90 / 128$ (49 \%) samples from rooms occupied by patients with disease. This corresponds with findings from another study of LTCF residents in which proportions of positive cultures from skin sites and environmental samples were highest among residents with disease, second highest among asymptomatic $C$. difficile colonized patients and lowest among non-colonized residents [9]. Moreover, Sethi and colleagues found that even 4 weeks after receiving therapy for $\mathrm{CDI}$, the frequency of skin contamination (30/52; $58 \%$ ) and environmental shedding (26/52; $50 \%)$ remained high in asymptomatic C. difficile colonized patients [81]. Samore and colleagues demonstrated that in an endemic situation carriage of $C$. difficile on the hands of healthcare workers was positively correlated with the extent of environmental contamination with C. difficile [82].

The spore-forming ability of $C$. difficile makes it distinct from other infectious organisms common to healthcare settings and introduces further challenges to reduce transmission. Spores can persist in the environment for long periods and require chlorine- [83] or peroxide-based [84] sporicidal agents or ultraviolet radiation devices [85] for environmental decontamination. Typically, hospital patients colonized with other multidrug-resistant organisms are isolated to prevent transmission, but this appears to be of limited value for asymptomatic $C$. difficile colonization. In an epidemiological model, Lanzas and colleagues demonstrated that transmission of $C$. difficile within a ward cannot be sustained unless new $C$. difficile colonized patients are introduced [86]. Therefore, the admission of asymptomatic $C$. difficile colonized patients plays an important role in sustaining $C$. difficile transmission within a ward [87]. A recent study, has demonstrated that nearly half of the $C$. difficile cases were genetically distinct from all previous cases, which suggests genetically diverse sources of infection [88]. Furthermore, Yakob and colleagues demonstrated, using a stochastic mathematical model, that screening for asymptomatic $C$. difficile colonization to segregate colonized patients from noncolonized patients had little impact on infection transmission because patients still in a latent period (exposed but not yet colonized) would not be detected [89].

\section{Risk factors for asymptomatic C. difficile colonization and progression to active disease}

Among inpatients with positive stool samples for $C$. difficile, McFarland and colleagues found that 52/83 (63\%) of the patients were asymptomatic and 31/83 (37 \%) developed symptoms of CDI [10]. Currently, the time required to progress from asymptomatic $C$. difficile colonization to active CDI is unknown; however, epidemiological studies have identified risk factors associated with progression to disease. It is not surprising to find common risk factors for asymptomatic $C$. difficile colonization and disease because colonization with $C$. difficile is a necessary prerequisite of disease. The most significant epidemiological study to date to investigate risk factors for healthcare-associated asymptomatic $C$. difficile colonization identified that hospitalization within the last 12 months, exposure to corticosteroids, history of CDI and presence of antibody against toxin B were significantly associated with healthcare-associated asymptomatic $C$. difficile colonization [90]. Similar findings were described by Loo and colleagues in 2011, they identified chemotherapy, recent hospitalization, use of proton-pump inhibitors or histamine $\mathrm{H} 2$ antagonists, and presence of antibodies against toxin $\mathrm{B}$ were associated with healthcare-associated asymptomatic $C$. difficile colonization [13]. The study also found that antibiotic exposure (within 8 weeks of hospitalization) was as a risk factor for healthcareassociated CDI (OR 5.25, 95 \% CI 2.15-12.82) but not for healthcare-associated asymptomatic $C$. difficile colonization (OR 1.04, 95 \% CI 0.61-1.78). The apparent discrepancy between the results may indicate that disruption of the intrinsic intestinal microbiota due to antibiotic exposure is not a key feature for $C$. difficile colonization as it is for progression to disease. More recently, an investigation conducted in a tertiary care facility identified recent hospitalization, chronic dialysis, and corticosteroid use as independent risk factors for toxigenic asymptomatic C. difficile colonization on admission [91]. The eligible patients' first stool samples after admission were tested for toxigenic $C$. difficile by real-time PCR assay. While the study had limited generalizability, because the subjects who participated in the study were predominantly older (mean age 64 years), and due to the low proportion of enrolled subjects who provided samples (22\%), results were consistent with a previous study that reported renal disease, prior hospital admission, and prior CDI as risk factors for culture positivity on admission [73].

There are limited data about risk factors for asymptomatic $C$. difficile colonization among healthy populations. McNamara and colleagues investigated environmental factors associated with an increased risk of asymptomatic $C$. difficile colonization in a cohort of healthy farm workers. They found that reported weekly exposure to lake or pond swimming was associated with asymptomatic $C$. difficile colonization [29]; although, no biological plausible explanations were given for this finding by the authors. A number of factors act in concert before asymptomatic $C$. difficile colonization progresses to active disease. These factors can be categorized as host mediated or pathogen 


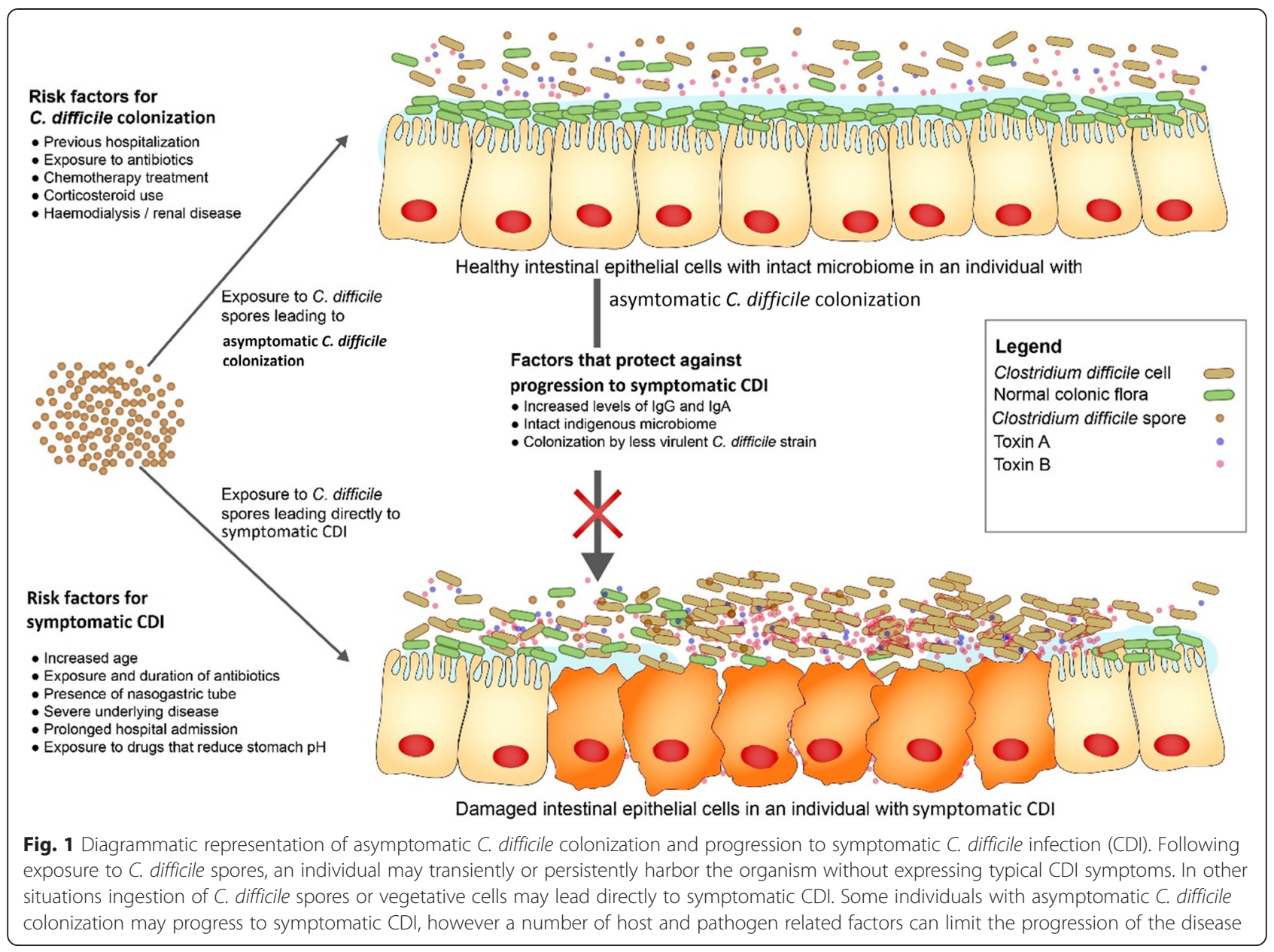

related. A diagrammatic representation of the mechanism of asymptomatic $C$. difficile colonization and progression to disease with risk factors is shown in Fig. 1.

\section{Host-mediated factors}

The most significant factor that leads to CDI is the disruption of intrinsic colonization resistance. This is a feature of the human intestine whereby indigenous microbiota, and the presence of compounds that inhibit bacterial germination and proliferation protect individuals against diseases caused by pathogenic organisms [54]. Factors that disrupt the intestinal microbiota thereby allowing $C$. difficile to flourish include treatment with antibiotics, proton-pump inhibitors, and chemotherapy agents in addition to physical effects of abdominal surgery and nasogastric tubes [13, 92].

Other host factors associated with an increased risk of CDI include advanced age, multiple comorbidities, suppressed immune system, inflammatory bowel disease and dense intestinal co-colonization with enterococci $[27,31,69,93-95]$. It is worth pointing out that the observed association between advanced age and multiple comorbidities infection, and the increased risk of CDI, may be confounded by medication exposure given that polypharmacy is common among these groups of patients.

There is substantial evidence that asymptomatic $C$. difficile colonization has a protective effect against progression to disease through an immune-mediated response. In a prospective study of hospital patients showed that at the time of colonization, IgG levels were higher in asymptomatic $C$. difficile colonized patients compared to patients who subsequently developed diarrhea [18]. The same authors demonstrated that patients with a single episode of diarrhea had increased IgM levels against toxins $\mathrm{A}, \mathrm{B}$ and non-toxin antigens compared to patients with recurrent disease, indicating that the presence of these antibodies conferred a protective effect [96]. Many healthy children and approximately $60 \%$ of adults have detectable serum IgG and IgA antibodies to $C$. difficile toxins $\mathrm{A}$ and $\mathrm{B}$, even when the organism is not detected $[97,98]$. If antibodies are stimulated during infancy and through further exposure to $C$. difficile from the environment [99], it would suggest that protection against CDI is a dynamic host-mediated characteristic $[18,100]$. The control of toxin-induced intestinal inflammation by 
up-regulation of $\mathrm{A}_{2 \mathrm{~B}}$ adenosine receptors in the intestinal epithelium can also reduce the progression of aggressive symptoms of disease [101]. In this study, an $A_{2 B}$ adenosine receptor antagonist did not reduce fecal toxin levels in animal models but conferred protection against progression of disease.

\section{Pathogen factors}

Colonization with non-toxigenic strains of $C$. difficile can offer protection against infection, suggesting a possible colonization resistance role through competition for nutrients or access to mucosal epithelial cells [55, 102]. Competition between clostridial strains may reduce the proliferation of pathogenic strains and the onset of disease symptoms [103]. Initial speculation was that toxigenic $C$. difficile strains may be in the minority among asymptomatic $C$. difficile colonized patients [104]; however, it has since been shown that the majority of strains are toxigenic.

\section{Discussion and conclusion}

Despite technological advances in C. difficile microbiology and epidemiology (e.g. genotyping), asymptomatic C. difficile colonization remains as a complex and challenging health problem as its epidemiological features vary considerably between study groups and settings. Several gaps in the current knowledge were identified in this review that should guide future research studies:

1. There is no consistent definition for asymptomatic C. difficile colonization; a standard definition across studies is urgently needed.

2. The time between acquisition of $C$. difficile and symptomatic disease is unknown but has been estimated to be between 1 and 2 weeks $[8,13,105]$. It has also been suggested that progression to disease happens within this short time after acquisition or does not occur at all [73].

3. Asymptomatic C. difficile colonized patients serve as a potential infection reservoir of horizontal transmission of $C$. difficile in a range of healthcare settings and the strain types isolated from patients with asymptomatic C. difficile colonization are predominantly toxigenic $[9,27,30,32,40,66,70,73,91,106]$. However, whether the clinical outcomes differ in asymptomatic patients colonized with toxigenic $C$. difficile compared to non-toxigenic strains it is currently unknown; thus, we suggest that patients with diarrheal symptoms with non-toxigenic strains of $C$. difficile should be considered colonized unless there is definitive evidence of disease.

4. Estimates of asymptomatic colonization may be underestimated as stool culture is not practical in a clinical setting; however, this constitutes important future epidemiological study.
The current SHEA guidelines for CDI recommend that active screening for asymptomatic $C$. difficile colonization is not performed for infection control purposes [19]. Polage and colleagues retrospectively reviewed 6121 records of toxin negative patients and revealed that only one $(0.02 \%)$ had a laboratory confirmed complication of CDI. We emphasize that this recommendation for asymptomatic $C$. difficile colonization is still valid for the following important reasons: first, there are limited options to manage asymptomatic $C$. difficile colonized patients - they should not be treated because antimicrobial therapy does not eradicate spores [19, 72]; moreover treatment may render patients more susceptible to symptomatic CDI [107]; and second, asymptomatic $C$. difficile colonization might protect individuals from progressing to active diseases [8].

Given the transmission potential of asymptomatic $C$. difficile colonized patients, the increased prevalence among certain clinical groups, limited management options, and the limited utility of screening, we suggest a more pragmatic approach. Intensive infection control practices, normally reserved for diseased patients, should be targeted at individuals or clinical areas with higher risk of asymptomatic $C$. difficile colonization. For example, patient or unit-level risk assessments could target enhanced environmental cleaning and use of gloves for patient contact to limit the transmission of $C$. difficile from asymptomatic C. difficile colonized patients [108]. Empirical research should be conducted into the impact of targeted, risk-based, intensive infection control programs before changes to the current SHEA guidelines for asymptomatic $C$. difficile colonized patients are considered.

\section{Additional file}

Additional file 1: Search strategy and selection criteria.

(DOCX $100 \mathrm{~kb})$

\section{Competing interests}

The authors declare that they have no competing interests.

\section{Authors' contributions}

The idea for this study was conceived by AC. The search was performed by LFK and JM. LFK and JM drafted the original manuscript. LY, TR, DP, NF, CH, $A C$ revised the manuscript and provided input. LFK, JM, LY, TR, DP, NF, CH, AC read and approved the final manuscript.

\section{Acknowledgments}

LFK is funded by an Endeavour Postgraduate Scholarship (\#3781_2014), an Australian National University Higher Degree Scholarship, and a Fondo para la Innovación, Ciencia y Tecnología Scholarship (\#095-FINCyT-BDE-2014). AC is funded by an Australian National Health and Medical Research Council Senior Research Fellowship (\#1058878).

\section{Author details}

${ }^{1}$ Research School of Population Health, The Australian National University, Building 62 Mills Road, Canberra ACT 2601, Australia. ${ }^{2}$ School of Population Health, The University of Queensland, Herston, QLD, Australia. ${ }^{3}$ Queensland Department of Health, Communicable Diseases Unit, Herston, QLD, Australia. ${ }^{4}$ Department of Disease Control, London School of Hygiene and Tropical 
Medicine, London, UK. ${ }^{5}$ Microbiology and Immunology, School of Pathology and Laboratory Medicine, The University of Western Australia, Nedlands, WA, Australia. ${ }^{6}$ PathWest Laboratory Medicine, Queen Elizabeth II Medical Centre, Nedlands, WA, Australia. ${ }^{7} T h e$ University of Queensland, UQ Centre for Clinical Research, Herston, QLD, Australia.

Received: 12 June 2015 Accepted: 31 October 2015 Published online: 14 November 2015

\section{References}

1. Hall I, O'Toole E. Intestinal flora in new-born infants: with a description of a new pathogenic anaerobe, Bacillus difficilis. Am J Dis Child. 1935;49:390-402.

2. Tattevin P, Buffet-Bataillon S, Donnio PY, Revest M, Michelet C. Clostridium difficile infections: do we know the real dimensions of the problem? Int J Antimicrob Agents. 2013;42:S36-40.

3. Lo Vecchio A, Zacur GM. Clostridium difficile infection: an update on epidemiology, risk factors, and therapeutic options. Curr Opin Gastroenterol. 2012;28:1-9.

4. Centers for Disease Control \& Prevention. Antibiotic Resistance Threats in the United States, 2013. U.S. Department of Health and Human Services. 2013. http://www.cdc.gov/drugresistance/threat-report-2013/pdf/ar-threats2013-508.pdf. Accessed Jun 2015.

5. Rupnik M, Wilcox MH, Gerding DN. Clostridium difficile infection: new developments in epidemiology and pathogenesis. Nat Rev Microbiol. 2009; $7: 526-36$

6. Voth DE, Ballard JD. Clostridium difficile toxins: mechanism of action and role in disease. Clin Microbiol Rev. 2005;18:247-63.

7. McFarland LV, Beneda HW, Clarridge JE, Raugi GJ. Implications of the changing face of Clostridium difficile disease for health care practitioners. Am J Infect Control. 2007:35:237-53.

8. Shim JK, Johnson S, Samore MH, Bliss DZ, Gerding DN. Primary symptomless colonisation by Clostridium difficile and decreased risk of subsequent diarrhoea. Lancet. 1998:351:633-6.

9. Riggs MM, Sethi AK, Zabarsky TF, Eckstein EC, Jump RL, Donskey CJ. Asymptomatic carriers are a potential source for transmission of epidemic and nonepidemic Clostridium difficile strains among long-term care facility residents. Clin Infect Dis. 2007:45:992-8.

10. McFarland LV, Mulligan ME, Kwok RY, Stamm WE. Nosocomial acquisition of Clostridium difficile infection. N Engl J Med. 1989;320:204-10

11. Brown E, Talbot GH, Axelrod P, Provencher M, Hoegg C. Risk factors for Clostridium difficile toxin-associated diarrhea. Infect Control Hosp Epidemiol. 1990;11:283-90.

12. Johnson S, Gerding DN, Olson MM, Weiler MD, Hughes RA, Clabots CR, et al. Prospective, controlled study of vinyl glove use to interrupt Clostridium difficile nosocomial transmission. Am J Med. 1990;88:137-40.

13. Loo VG, Bourgault AM, Poirier L, Lamothe F, Michaud S, Turgeon N, et al. Host and pathogen factors for Clostridium difficile infection and colonization. N Engl J Med. 2011;365:1693-703.

14. Clements AC, Magalhaes RJ, Tatem AJ, Paterson DL, Riley TV. Clostridium difficile PCR ribotype 027: assessing the risks of further worldwide spread. Lancet Infect Dis. 2010:10:395-404.

15. Viscidi R, Willey S, Bartlett JG. Isolation rates and toxigenic potential of Clostridium difficile isolates from various patient populations. Gastroenterology. 1981;81:5-9.

16. Gerding DN, Johnson S, Peterson LR, Mulligan ME, Silva Jr J. Clostridium difficile-associated diarrhea and colitis. Infect Control Hosp Epidemiol. 1995:16:459-77.

17. Planche TD, Davies KA, Coen PG, Finney JM, Monahan IM, Morris KA, et al. Differences in outcome according to Clostridium difficile testing method: a prospective multicentre diagnostic validation study of $C$. difficile infection. Lancet Infect Dis. 2013;13:936-45.

18. Kyne L, Warny M, Qamar A, Kelly CP. Asymptomatic carriage of Clostridium difficile and serum levels of $\mathrm{lg} \mathrm{G}$ antibody against toxin A. N Engl J Med. 2000;342:390-7.

19. Cohen SH, Gerding DN, Johnson S, Kelly CP, Loo VG, McDonald LC, et al. Clinical practice guidelines for Clostridium difficile infection in adults: 2010 update by the society for healthcare epidemiology of America (SHEA) and the infectious diseases society of America (IDSA). Infect Control Hosp Epidemiol. 2010:31:431-55.

20. Polage CR, Solnick JV, Cohen SH. Nosocomial diarrhea: evaluation and treatment of causes other than Clostridium difficile. Clin Infect Dis. 2012;55:982-9.
21. MCFarland LV. Epidemiology of infectious and iatrogenic nosocomial diarrhea in a cohort of general medicine patients. Am J Infect Control. 1995;23:295-305.

22. Gerding DN, Olson MM, Peterson LR, Teasley DG, Gebhard RL, Schwartz ML, et al. Clostridium difficile-associated diarrhea and colitis in adults. A prospective case-controlled epidemiologic study. Arch Intern Med. 1986;146:95-100.

23. Geric B, Carman RJ, Rupnik M, Genheimer CW, Sambol SP, Lyerly DM, et al. Binary Toxin-Producing, Large Clostridial Toxin-Negative Clostridium difficile Strains Are Enterotoxic but Do Not Cause Disease in Hamsters. J Infect Dis. 2006;193:1143-50

24. Natarajan M, Walk ST, Young VB, Aronoff DM. A clinical and epidemiological review of non-toxigenic Clostridium difficile. Anaerobe. 2013;22:1-5.

25. Behroozian AA, Chludzinski JP, Lo ES, Ewing SA, Waslawski S, Newton DW, et al. Detection of mixed populations of Clostridium difficile from symptomatic patients using capillary-based polymerase chain reaction ribotyping. Infect Control Hosp Epidemiol. 2013;34:961-6.

26. Stojanović P, Stojanović N, Kocic B, Stanković-Dordević D, Babić T, Stojanović K. Asymptomatic carriers of Clostridium difficile in serbian population. Cent Eur J Med. 2012;7:769-74.

27. Ozaki E, Kato H, Kita H, Karasawa T, Maegawa T, Koino Y, et al. Clostridium difficile colonization in healthy adults: transient colonization and correlation with enterococcal colonization. J Med Microbiol. 2004:53:167-72.

28. Miyajima F, Roberts P, Swale A, Price V, Jones M, Horan M, et al. Characterisation and carriage ratio of Clostridium difficile strains isolated from a community-dwelling elderly population in the United Kingdom. PLOS ONE. 2011;6, e22804.

29. MCNamara SE, Abdujamilova N, Somsel P, Gordoncillo MJ, DeDecker JM, Bartlett PC. Carriage of Clostridium difficile and other enteric pathogens among a 4-H avocational cohort. Zoonoses Public Health. 2011;58:192-9.

30. Arvand M, Moser V, Schwehn C, Bettge-Weller G, Hensgens MP, Kuijper EJ. High prevalence of Clostridium difficile colonization among nursing home residents in Hesse Germany. PLoS ONE. 2012;7:e30183.

31. Aronsson B, Mollby R, Nord CE. Antimicrobial agents and Clostridium difficile in acute enteric disease: Epidemiological data from Sweden, 1980-1982. J Infect Dis. 1985;151:476-81.

32. Kato H, Kita H, Karasawa T, Maegawa T, Koino Y, Takakuwa H, et al. Colonisation and transmission of Clostridium difficile in healthy individuals examined by PCR ribotyping and pulsed-field gel electrophoresis. J Med Microbiol. 2001;50:720-7.

33. Galdys AL, Nelson JS, Shutt KA, Schlackman JL, Pakstis DL, Pasculle AW, et al. Prevalence and duration of asymptomatic Clostridium difficile carriage among healthy subjects in Pittsburgh Pennsylvania. J Clin Microbiol. 2014:52:2406-9.

34. Rousseau C, Levenez F, Fouqueray C, Dore J, Collignon A, Lepage P. Clostridium difficile colonization in early infancy is accompanied by changes in intestinal microbiota composition. J Clin Microbiol. 2011:49:858-65.

35. Belmares J, Johnson S, Parada JP, Olson MM, Clabots CR, Bettin KM, et al. Molecular epidemiology of Clostridium difficile over the course of 10 years in a tertiary care hospital. Clin Infect Dis. 2009;49:1141-7.

36. Bender BS, Bennett R, Laughon BE, Greenough 3rd WB, Gaydos C, Sears SD, et al. Is Clostridium difficile endemic in chronic-care facilities? Lancet. 1986;2:11-3.

37. Campbell RR, Beere D, Wilcock GK, Brown EM. Clostridium difficile in acute and long-stay elderly patients. Age Ageing. 1988;17:333-6.

38. Bauer MP, Farid A, Bakker M, Hoek RA, Kuijper EJ, van Dissel JT. Patients with cystic fibrosis have a high carriage rate of non-toxigenic Clostridium difficile. Clin Microbiol Infect. 2014;20:1469-0691.

39. Peach SL, Borriello SP, Gaya H, Barclay FE, Welch AR. Asymptomatic carriage of Clostridium difficile in patients with cystic fibrosis. J Clin Pathol. 1986:39:1013-8.

40. Welkon CJ, Long SS, Thompson Jr CM, Gilligan PH. Clostridium difficile in patients with cystic fibrosis. Am J Dis Child. 1985;139:805-8.

41. Yahav J, Samra Z, Blau H, Dinari G, Chodick G, Shmuely H. Helicobacter pylori and Clostridium difficile in cystic fibrosis patients. Dig Dis Sci. 2006;51:2274-9.

42. Pant C, Sferra TJ, Deshpande A, Olyaee M, Gilroy R, Anderson MP, et al. Clostridium difficile infection in hospitalized patients with cystic fibrosis. Infect Control Hosp Epidemiol. 2014;35:1547-8.

43. Dumford 3rd DM, Nerandzic M, Chang S, Richmond MA, Donskey C. Epidemiology of Clostridium difficile and vancomycin-resistant Enterococcus colonization in patients on a spinal cord injury unit. J Spinal Cord Med. 2011;34:22-7.

44. Stevens V, Dumyati G, Fine LS, Fisher SG, van Wijngaarden E. Cumulative Antibiotic Exposures Over Time and the Risk of Clostridium difficile Infection. Clin Infect Dis. 2011;53:42-8. 
45. Marciniak C, Chen D, Stein AC, Semik PE. Prevalence of Clostridium difficile colonization at admission to rehabilitation. Arch Phys Med Rehabil. 2006;87:1086-90

46. Gerding DN, Muto CA, Owens Jr RC. Measures to control and prevent Clostridium difficile infection. Clin Infect Dis. 2008;46:S43-9.

47. Jump RL, Pultz MJ, Donskey CJ. Vegetative Clostridium difficile survives in room air on moist surfaces and in gastric contents with reduced acidity: a potential mechanism to explain the association between proton pump inhibitors and C. difficile-associated diarrhea? Antimicrob Agents Chemother. 2007:51:2883-7.

48. Sarker MR, Paredes-Sabja D. Molecular basis of early stages of Clostridium difficile infection: germination and colonization. Future Microbiol. 2012;7:933-43.

49. Testore GP, Nardi F, Babudieri S, Giuliano M, Di Rosa R, Panichi G. Isolation of Clostridium difficile from human jejunum: identification of a reservoir for disease? J Clin Pathol. 1986:39:861-2.

50. Spigaglia P, Barketi-Klai A, Collignon A, Mastrantonio P, Barbanti F, Rupnik M, et al. Surface-layer (S-layer) of human and animal Clostridium difficile strains and their behaviour in adherence to epithelial cells and intestinal colonization. J Med Microbiol. 2013;62:1386-93.

51. Buffie CG, Bucci V, Stein RR, McKenney PT, Ling L, Gobourne A, et al. Precision microbiome reconstitution restores bile acid mediated resistance to Clostridium difficile. Nature. 2015;517:205-8.

52. Rea MC, O'Sullivan O, Shanahan F, OToole PW, Stanton C, Ross RP, et al. Clostridium difficile carriage in elderly subjects and associated changes in the intestinal microbiota. J Clin Microbiol. 2012;50:867-75.

53. Vincent C, Stephens DA, Loo VG, Edens TJ, Behr MA, Dewar K, et al. Reductions in intestinal Clostridiales precede the development of nosocomial Clostridium difficile infection. Microbiome. 2013;1:2049-618.

54. Britton RA, Young VB. Interaction between the intestinal microbiota and host in Clostridium difficile colonization resistance. Trends Microbiol. 2012;20:313-9.

55. Gerding DN, Meyer T, Lee C, Cohen SH, Murthy UK, Poirier A, et al. Administration of spores of nontoxigenic Clostridium difficile strain m3 for prevention of recurrent $\mathrm{c}$ difficile infection: A randomized clinical trial. JAMA. 2015:313:1719-27.

56. Brouwer MSM, Roberts AP, Hussain H, Williams RJ, Allan E, Mullany P. Horizontal gene transfer converts non-toxigenic Clostridium difficile strains into toxin producers. Nat Commun. 2013;4:42601.

57. Ishida Y, Maegawa T, Kondo T, Kimura A, Iwakura Y, Nakamura S, et al. Essential involvement of IFN-gamma in Clostridium difficile toxin A-induced enteritis. J Immunol. 2004;172:3018-25.

58. Meyer GK, Neetz A, Brandes G, Tsikas D, Butterfield JH, Just I, et al. Clostridium difficile toxins $A$ and $B$ directly stimulate human mast cells. Infect Immun. 2007:75:3868-76

59. Carroll KC, Bartlett JG. Biology of Clostridium difficile: implications for epidemiology and diagnosis. Annu Rev Microbiol. 2011;65:501-21.

60. Lyerly DM, Saum KE, MacDonald DK, Wilkins TD. Effects of Clostridium difficile toxins given intragastrically to animals. Infect Immun. 1985:47:349-52.

61. Komatsu M, Kato H, Aihara M, Shimakawa K, Iwasaki M, Nagasaka Y, et al. High frequency of antibiotic-associated diarrhea due to toxin A-negative, toxin B-positive Clostridium difficile in a hospital in Japan and risk factors for infection. Eur J Clin Microbiol Infect Dis. 2003:22:525-9.

62. Drudy D, Fanning S, Kyne L. Toxin A-negative, toxin B-positive Clostridium difficile. Int J Infect Dis. 2007:11:5-10.

63. Steele J, Mukherjee J, Parry N, Tzipori S. Antibody Against TcdB, but Not TcdA, Prevents Development of Gastrointestinal and Systemic Clostridium difficile Disease. J Infect Dis. 2013;207:323-30.

64. Lyras D, O'Connor JR, Howarth PM, Sambol SP, Carter GP, Phumoonna T, et al. Toxin B is essential for virulence of Clostridium difficile. Nature. 2009;458:1176-9.

65. Kuehne SA, Cartman ST, Heap JT, Kelly ML, Cockayne A, Minton NP. The role of toxin A and toxin B in Clostridium difficile infection. Nature. 2010;467:711-3.

66. Walker KJ, Gilliland SS, Vance-Bryan K, Moody JA, Larsson AJ, Rotschafer JC, et al. Clostridium difficile colonization in residents of long-term care facilities: prevalence and risk factors. J Am Geriatr Soc. 1993:41:940-6.

67. Simor $A E$, Yake SL, Tsimidis K. Infection due to Clostridium difficile among elderly residents of a long-term-care facility. Clin Infect Dis. 1993;17:672-8.

68. Corrado OJ, Mascie-Taylor BH, Hall MJ, Bolton RP. Prevalence of Clostridium difficile on a mixed-function ward for the elderly. J Infect. 1990;21:287-92
69. Cefai C, Elliott TS, Woodhouse KW. Gastrointestinal carriage rate of Clostridium difficile in elderly, chronic care hospital patients. J Hosp Infect. 1988;11:335-9.

70. Ryan J, Murphy C, Twomey C, Paul Ross R, Rea MC, MacSharry J, et al. Asymptomatic carriage of Clostridium difficile in an Irish continuing care institution for the elderly: prevalence and characteristics. Ir J Med Sci. 2010;179:245-50

71. Zidaric V, Kevorkijan BK, Oresic N, Janezic S, Rupnik M. Comparison of two commercial molecular tests for the detection of Clostridium difficile in the routine diagnostic laboratory. J Med Microbiol. 2011;60:1131-6.

72. Johnson S, Homann SR, Bettin KM, Quick JN, Clabots CR, Peterson LR, et al. Treatment of asymptomatic Clostridium difficile carriers (fecal excretors) with vancomycin or metronidazole. A randomized, placebo-controlled trial. Ann Intern Med. 1992;117:297-302.

73. Samore MH, DeGirolami PC, Tlucko A, Lichtenberg DA, Melvin ZA, Karchmer AW. Clostridium difficile Colonization and Diarrhea at a Tertiary Care Hospital. Clin Infect Dis. 1994;18:181-7.

74. Kim KH, Fekety R, Batts DH, Brown D, Cudmore M, Silva Jr J, et al. Isolation of Clostridium difficile from the environment and contacts of patients with antibiotic-associated colitis. J Infect Dis. 1981;143:42-50.

75. Curry SR, Muto CA, Schlackman JL, Pasculle AW, Shutt KA, Marsh JW, et al. Use of Multilocus Variable Number of Tandem Repeats Analysis Genotyping to Determine the Role of Asymptomatic Carriers in Clostridium difficile Transmission. Clin Infect Dis. 2013;57:1094-102

76. Malamou-Ladas H, O'Farrell S, Nash JQ, Tabaqchali S. Isolation of Clostridium difficile from patients and the environment of hospital wards. J Clin Pathol. 1983;36:88-92.

77. Savage AM, Alford RH. Nosocomial spread of Clostridium difficile. Infect Control. 1983:4:31-3.

78. Barbut F, Petit JC. Epidemiology of Clostridium difficile-associated infections. Clin Microbiol Infect. 2001:7:405-10.

79. Clabots CR, Johnson S, Olson MM, Peterson LR, Gerding DN. Acquisition of Clostridium difficile by hospitalized patients: evidence for colonized new admissions as a source of infection. J Infect Dis. 1992;166:561-7.

80. Jinno S, Kundrapu S, Guerrero DM, Jury LA, Nerandzic MM, Donskey CJ. Potential for transmission of Clostridium difficile by asymptomatic acute care patients and long-term care facility residents with prior $C$. difficile infection Infect Control Hosp Epidemiol. 2012;33:638-9.

81. Sethi AK, Al-Nassir WN, Nerandzic MM, Bobulsky GS, Donskey CJ. Persistence of skin contamination and environmental shedding of Clostridium difficile during and after treatment of $\mathrm{C}$. difficile infection. Infect Control Hosp Epidemiol. 2010;31:21-7.

82. Samore MH, Venkataraman L, DeGirolami PC, Arbeit RD, Karchmer AW. Clinical and molecular epidemiology of sporadic and clustered cases of nosocomial Clostridium difficile diarrhea. Am J Med. 1996;100:32-40.

83. Wilcox MH, Fawley WN, Wigglesworth N, Parnell P, Verity P, Freeman J. Comparison of the effect of detergent versus hypochlorite cleaning on environmental contamination and incidence of Clostridium difficile infection. J Hosp Infect. 2003;54:109-14.

84. Boyce JM, Havill NL, Otter JA, McDonald LC, Adams NM, Cooper T, et al, Impact of hydrogen peroxide vapor room decontamination on Clostridium difficile environmental contamination and transmission in a healthcare setting. Infect Control Hosp Epidemiol. 2008;29:723-9.

85. Nerandzic MM, Cadnum JL, Pultz MJ, Donskey CJ. Evaluation of an automated ultraviolet radiation device for decontamination of Clostridium difficile and other healthcare-associated pathogens in hospital rooms. BMC Infect Dis. 2010:10:1471-2334.

86. Lanzas C, Dubberke ER, Lu Z, Reske KA, Grohn YT. Epidemiological mode for Clostridium difficile transmission in healthcare settings. Infect Control Hosp Epidemiol. 2011;32:553-61.

87. Walker AS, Eyre DW, Wyllie DH, Dingle KE, Harding RM, O'Connor L, et al. Characterisation of Clostridium difficile hospital ward-based transmission using extensive epidemiological data and molecular typing. PLoS Med. 2012:9:7.

88. Eyre DW, Cule ML, Wilson DJ, Griffiths D, Vaughan A, O'Connor L, et al. Diverse sources of $C$. difficile infection identified on whole-genome sequencing. N Engl J Med. 2013;369:1195-205.

89. Yakob L, Riley TV, Paterson DL, Clements AC. Clostridium difficile exposure as an insidious source of infection in healthcare settings: an epidemiological model. BMC Infect Dis. 2013;13:376.

90. Kong LY, Dendukuri N, Schiller I, Bourgault AM, Brassard P, Poirier L, et al. Predictors of asymptomatic Clostridium difficile colonization on hospital admission. Am J Infect Control. 2015:43:248-53. 
91. Leekha S, Aronhalt KC, Sloan LM, Patel R, Orenstein R. Asymptomatic Clostridium difficile colonization in a tertiary care hospital: Admission prevalence and risk factors. Am J Infect Control. 2013;41:390-3.

92. Gerding DN, Olson MM, Johnson S, Peterson LR, Lee Jr JT. Clostridium difficile diarrhea and colonization after treatment with abdominal infection regimens containing clindamycin or metronidazole. Am J Surg. 1990:159:212-7.

93. Nakamura S, Mikawa M, Nakashio S, Takabatake M, Okado I, Yamakawa K, et al. Isolation of Clostridium difficile from the feces and the antibody in sera of young and elderly adults. Microbiol Immunol. 1981;25:345-51.

94. Morris Jr JG, Janvis WR, Nunez-Montiel OL, Towns ML, Thompson FS, Dowell VR, et al. Clostridium difficile Colonization and toxin production in a cohort of patients with malignant hematologic disorders. Arch Intern Med. 1984;144:967-9.

95. Clayton EM, Rea MC, Shanahan F, Quigley EM, Kiely B, Hill C, et al. The vexed relationship between Clostridium difficile and inflammatory bowel disease: an assessment of carriage in an outpatient setting among patients in remission. Am J Gastroenterol. 2009;104:1162-9.

96. Kyne L, Warny M, Qamar A, Kelly CP. Association between antibody response to toxin $A$ and protection against recurrent Clostridium difficile diarrhoea. Lancet. 2001;357:189-93.

97. Sanchez-Hurtado K, Corretge M, Mutlu E, Mcllhagger R, Starr JM, Poxton IR. Systemic antibody response to Clostridium difficile in colonized patients with and without symptoms and matched controls. J Med Microbiol. 2008;57:717-24.

98. Kelly CP. Immune response to Clostridium difficile infection. Eur J Gastroenterol Hepatol. 1996;8:1048-53.

99. Kelly CP, Kyne L. The host immune response to Clostridium difficile. J Med Microbiol. 2011;60:1070-9.

100. Warny M, Vaerman JP, Avesani V, Delmee M. Human antibody response to Clostridium difficile toxin A in relation to clinical course of infection. Infect Immun. 1994;62:384-9.

101. Warren CA, Li Y, Calabrese GM, Freire RS, Zaja-Milatovic S, van Opstal E, et al. Contribution of adenosine $A(2 B)$ receptors in Clostridium difficile intoxication and infection. Infect Immun. 2012:80:4463-73.

102. Sambol SP, Merrigan MM, Tang JK, Johnson S, Gerding DN. Colonization for the prevention of Clostridium difficile disease in hamsters. J Infect Dis. 2002;186:1781-9.

103. Yakob L, Riley TV, Paterson DL, Marquess J, Magalhaes RJ, Furuya-Kanamori L, et al. Mechanisms of hypervirulent Clostridium difficile ribotype 027 displacement of endemic strains: an epidemiological model. Sci Rep. 2015;5:12666.

104. Burdon DW. Clostridium difficile: the epidemiology and prevention of hospital-acquired infection. Infection. 1982;10:203-4.

105. Johnson S, Clabots CR, Linn FV, Olson MM, Peterson LR, Gerding DN. Nosocomial Clostridium difficile colonisation and disease. Lancet. 1990;336:97-100.

106. Guerrero DM, Becker JC, Eckstein EC, Kundrapu S, Deshpande A, Sethi AK, et al. Asymptomatic carriage of toxigenic Clostridium difficile by hospitalized patients. J Hosp Infect. 2013;85:155-8.

107. Johnson S. Recurrent Clostridium difficile infection: a review of risk factors, treatments, and outcomes. J Infect. 2009;58:403-10.

108. Yakob L, Riley TV, Paterson DL, Marquess J, Clements ACA. Assessing control bundles for Clostridium difficile: a review and mathematical model. Emerg Microbes Infect. 2014;3:e43.

109. Hung YP, Tsai PJ, Hung KH, Liu HC, Lee Cl, Lin HJ, et al. Impact of Toxigenic Clostridium difficile Colonization and Infection among Hospitalized Adults at a District Hospital in Southern Taiwan. PLoS ONE. 2012;7, e42415.

110. Al-Jumaili IJ, Shibley M, Lishman AH, Record CO. Incidence and origin of Clostridium difficile in neonates. J Clin Microbiol. 1984;19:77-8.

111. Jangi S, Lamont JT. Asymptomatic colonization by Clostridium difficile in infants: implications for disease in later life. J Pediatr Gastroenterol Nutr. 2010;51:2-7

112. Penders J, Thijs C, Vink C, Stelma FF, Snijders B, Kummeling I, et al. Factors influencing the composition of the intestinal microbiota in early infancy. Pediatrics. 2006;118:511-21.

113. Stark PL, Lee A, Parsonage BD. Colonization of the large bowel by Clostridium difficile in healthy infants: quantitative study. Infect Immun. 1982;35:895-9.

114. Rudensky B, Rosner S, Sonnenblick M, van Dijk Y, Shapira E, Isaacsohn M. The prevalence and nosocomial acquisition of Clostridium difficile in elderly hospitalized patients. Postgrad Med J. 1993;69:45-7.

115. Rivera EV, Woods S. Prevalence of asymptomatic Clostridium difficile colonization in a nursing home population: A cross-sectional study. J Gend Specif Med. 2003;6:27-30.
116. Fulton JD, Fallon RJ. Is Clostridium difficile endemic in chronic-care facilities? Lancet. 1987:2:393-4.

117. Schoevaerdts D, Swine C, Verroken A, Huang TD, Glupczynski Y. Asymptomatic colonization by Clostridium difficile in older adults admitted to a geriatric unit: a prospective cohort study. J Am Geriatr Soc. 2011;59:2179-81.

118. McCoubrey J, Starr J, Martin H, Poxton IR. Clostridium difficile in a geriatric unit: a prospective epidemiological study employing a novel S-layer typing method. J Med Microbiol. 2003;52:573-8.

119. McFarland LV, Surawicz CM, Stamm WE. Risk factors for Clostridium difficile carriage and C. difficile-associated diarrhea in a cohort of hospitalized patients. J Infect Dis. 1990;162:678-84.

120. Heard SR, O'Farrell S, Holland D, Crook S, Barnett MJ, Tabaqchali S. The epidemiology of Clostridium difficile with use of a typing scheme: nosocomial acquisition and cross-infection among immunocompromised patients. J Infect Dis. 1986;153:159-62.

121. Barbut F, Corthier G, Charpak Y, Cerf M, Monteil H, Fosse T, et al. Prevalence and pathogenicity of Clostridium difficile in hospitalized patients. A French multicenter study. Arch Intern Med. 1996;156:1449-54.

122. Mainardi JL, Lacassin F, Guilloy Y, Goldstein FW, Leport C, Acar JF, et al. Low rate of Clostridium difficile colonization in ambulatory and hospitalized HIV-infected patients in a hospital unit: a prospective survey. J Infect. 1998;37:108-11.

123. Hell M, Sickau K, Chmelizek G, Kern JM, Maass M, Huhulescu S, et al. Absence of Clostridium difficile in asymptomatic hospital staff. Am J Infect Control. 2012;40(10):1023-4.

124. Privitera G, Scarpellini P, Ortisi G, Nicastro G, Nicolin R, de Lalla F. Prospective study of Clostridium difficile intestinal colonization and disease following single-dose antibiotic prophylaxis in surgery. Antimicrob Agents Chemother. 1991;35:208-10.

125. Rotimi VO, Jamal WY, Mokaddas EM, Brazier JS, Johny M, Duerden BI. Prevalent PCR ribotypes of clinical and environmental strains of Clostridium difficile isolated from intensive-therapy unit patients in Kuwait. J Med Microbiol. 2003;52:705-9.

\section{Submit your next manuscript to BioMed Central and take full advantage of:}

- Convenient online submission

- Thorough peer review

- No space constraints or color figure charges

- Immediate publication on acceptance

- Inclusion in PubMed, CAS, Scopus and Google Scholar

- Research which is freely available for redistribution 